\title{
ON THE RELATIONSHIP OF KITSCH AND PERSUASION
}

DOROTA DĄBROWSKA

Faculty of Humanities,

Cardinal Stefan Wyszyński University in Warsaw

dkdabrowska@gmail.com

The attempt made in this text to reflect on the relations between kitsch and persuasion is motivated by the feeling that although these concepts belong to different orders (the former is an aesthetic category, while the latter is used in interdisciplinary analyses of the process of influencing the audience), there is often a significant co-existence of these concepts within a given work. The analysis of this interdependence - and its concrete cultural implementations - may result in a deeper understanding of both phenomena.

The relationship I am interested in has two facets: one marked by obviousness, the other by ambiguity. The former is connected with the presence of persuasion in kitsch (including the possibility of recognizing it as its basic building material), while the latter is connected with generating kitsch through persuasive transmissions. I will begin with the former.

Regardless of how we understand persuasion, it seems to be an indispensable component of kitsch. Its way of existence and purpose are connected with the pursuit of unambiguity, seduction leading to specific experiences. Kitsch deprives its recipient of individuality, and its action is aimed at achieving a specific effect. The unification inscribed in it is not only a side effect of seduction, but actually its expected result - the experience of community brings relief, deepens the state of being moved, the sense of familiarity.

Kitsch causes two tears to flow in quick succession. The first tear says: How nice to see children running on the grass! The second tear says: How nice to be moved, together with all mankind, by children running on the grass! 
It is the second tear that makes kitsch kitsch. The brotherhood of man on earth will be possible only on a base of kitsch (Kundera 1984: 251).

Making the audience similar, making them a homogeneous mass, is the basis of the 'kitsch experience' (Banach 1986: 52). The experience of relief and soothing inscribed in them results from the lack of individual responsibility, from the sense of security - reminiscent of the one experienced by a child under the care of loving parents:

In the realm of kitsch, the dictatorship of the heart reigns supreme.

The feeling induced by kitsch must be a kind the multitudes can share. Kitsch may not, therefore, depend on an unusual situation; it must derive from the basic images people have engraved in their memories: the ungrateful daughter, the neglected father, children running on the grass, the motherland betrayed, first love (Kundera 1984: 250-251).

Andrzej Banach (1986: 64), juxtaposing the aesthetic experience and kitsch, concludes:

The last feature of the kitsch aesthetic experience is its collectivity. In a pure aesthetic experience, a person wants to be alone. Even a whisper bothers them. In the kitsch experience, where the body has a big role, the person becomes a part of the whole, an element of the collective.

Kitsch is usually connected with the intention of a clear, expressive message (Wójcik 2000). leaving no room for reflection. It aims to organize the world, deprive the recipient of anxiety, move them. However, unlike the shocking, 'tumultuous' experience of catharsis, it is supposed to deepen or restore the state of comfort with the power of the tension-breaking solution. It includes 'intelligibility and clarity understood as an imperative of direct, undisturbed and immediate access to the recipient' (Citko 2000: 117). Abraham Moles (1978: 219) describes kitsch as 'totalitarianism without violence', Andrzej Banach (1986: 33) says that it is 'a very dangerous object, even an enemy,' calling it 'a work of deception', indicating that 'at the basis of its construction is the will to lead the good-natured recipient where the artist likes'. This can happen more or less clearly. Banach, while developing the theme of danger inscribed in kitsch, notes: 
If kitsch seems dangerous to us, it is precisely because someone hidden outside the artist, or even the artist themselves, gives us a signal, and we, unaware of it, succumb to it. The mechanism of kitsch is the evocation of reflexes that seem inborn, inherited (ibid.: 147).

Thus, kitsch turns into a mysterious tool of control, preventing free and unrestrained interpretation of the reality by the recipient. Banach also calls attention to the automation of the kitsch process (ibid.: 147).

When considering the category I am interested in, it is often pointed out that although cheapness and technical mediocrity are fundamentally inscribed in kitsch, sometimes - and even mostly - we are dealing with a qualitatively different variant of kitsch. Considering the etymology of the word 'kitsch' from the point of view of its relationship with the word 'sketch', Banach concludes:

Unfortunately, the similarity between sketch and kitsch is exhausted in the sphere of sound. Apart from that, everything divides them. Today's kitsch (...) is often perfectly finished, expensive, magnificent, appealing to the audience (ibid.: 10).

One of the basic criteria of kitsch turns out to have the status of alternative, optional and unnecessary. Although its mediocrity, temporality and imitativeness seem to be its basic features, in the end their lack does not deprive the object/work of its 'kitsch' identity. Paolo Sorrentino's film Youth, analyzed by Maria Beszterda (2015) from the point of view of the dangerous closeness of pathos and sublimity and kitsch, can be regarded as an example of a work that suitably represents the quality described above. Although formal sophistication and originality are the opposite of the carelessness and mediocrity of mass productions, they do not automatically guarantee the status of a work of art. Katarzyna Citko (2000: 117) considers the 'accumulation of non-functional effects and ornaments' to be one of the essential features of kitsch'. The surplus in terms of aesthetic complexity of the work threatens with pretentiousness ${ }^{1}$ - this remark indicates the necessity to go beyond

1 'Pretentiousness as a claim, asking for more than one should, taking on better appearances, calculating on overgrowth, pretending to be bigger, more perfect. We will find all these features in perfect condition in kitsch as its essential ingredient' (Banach 1986: 78). 
aesthetic criteria in the analysis and interpretation of kitsch to reflect on the function of the means used.

The observation indicating the alternative nature of the criteria for kitsch makes us think about the extent to which particular features assigned to it must be represented in a given object in order to be able to adequately define its identity as 'kitsch.'

Works that go beyond the aesthetic sphere, capturing kitsch in ethical categories, inspire reflection on the relations between kitsch and persuasion. In the introduction to the Polish-language edition of Saul Friedländer's Reflections of Nazism: An Essay on Kitsch and Death, Paweł Śpiewak (2011: 10-11) makes a radical statement:

Kitsch (...) is sometimes described as bad art, shameless, degraded beauty, and it should be simply called a lie. If we do so, we will probably call it evil as well, and then it will turn out that what was considered to be a question of taste, aesthetics, and attitude towards beauty acquires an ethical character. These two approaches, aesthetic and ethical, are mixed up in numerous treatises on kitsch and turn out to be inseparable.

The above considerations do not boil down to stating that what is aesthetically of little value is unworthy of human cognition, or that the seemingly innocent 'trash' can be harmful. They also reflect on the particular potential of this 'bad art' leading to the shaping of mass imagination. The example of Nazi kitsch very clearly reveals the burden of this impact.

The second face of the relation between kitsch and persuasion, which I described as marked with ambiguity, reveals itself in the question about the possibility of 'creating' kitsch by persuasion, and thus the presence of this category - with a strictly aesthetic status - somehow independently of the aesthetic identity of the work. The above observation that it is impossible to treat purely formal reasons as determinants of a work's kitschiness (since kitsch - as I will try to point out further - may also appear in refined and original creations), leads to the statement that in an attempt to identify a work from the point of view of the presence of the category we are interested in, we are forced to analyze and interpret its elements in the context of the whole, to recognize this 'cheapness' on various levels. One may assume that there is a special bond between kitsch 
and those texts of culture which deprive the viewer of their subjectivity and therefore consider them to be strictly programmed for specific experiences and conclusions. Due to this 'cheapness,' the conventionality - which does not quite openly aim at winning the viewer over - we intuitively perceive propaganda and biased works as kitsch.

Persuasion is a more general concept, indicating any kind of attempt to convince people to accept a particular way of understanding reality. Unlike works of a propagandistic nature, in works that we would be inclined to treat as persuasive (leaning towards using a more general, less defined category), we may be dealing with subtlety, ambiguity, artistic sophistication (Sasaki 2003: 4-5). At the same time, however, cultural texts of a persuasive nature - regardless of their formal complexity - are usually focused on the idea of a strictly defined influence on the viewer, which subordinates all elements of the work to itself, turning them into an artifact with a status close to a political manifesto. Such a message is usually devoid of directness, the 'convincing' inscribed in the persuasion is not done quite openly ${ }^{2}$. Of course, due to the generality of the meaning of this term, we will also encounter phenomena which, although described as persuasive, are not characterized by the features indicated above. In this discussion, I limit myself to one of the many ways of understanding persuasion, indicating its similarity to propaganda (see: Garpiel 2003: 37-41).

An example of a cultural text in which the categories we are interested in - kitsch and persuasion - are closely connected is the pop-culture film God's Not Dead (2014) directed by Harold Cronk. In this case, one could even speak of the propaganda character of the work, which does not change the direction of the analysis indicated here (since I treat propaganda as one of the varieties of persuasion). The film tells the story of a young student of an American

2 'The observer of mass culture must, however, be interested in a specific kind of conative function: it does not externalise so much in all possible functions of the factors of expression whose task is to refer to the recipient, but rather in those particular factors which determine or attempt to determine the behaviour (mental or physical) of the recipient, and to do so in an indirect way, in a way concealed, as it were, not through direct prohibitions or orders. I would propose calling this particular variant of the conative function the persuasive function' (Barańczak 1983: 30). 
university, a participant in a philosophy course. The instructor treats the statement 'God is dead' as a kind of starting point, a kind of condition for participation in the class, which each of the participants is to 'sign'. The protagonist of the film, Josh, due to his personal convictions, is not ready to meet this expectation, which is why he is faced with a challenge - the condition to pass the course is to convince the rest of the students of the falsity of the claim propagated by the lecturer. The plot of the film focuses on Josh's struggle - the inner struggle to stay faithful to his values and attempts to address the intellectual challenge. As one would expect from the first minutes of the film, these efforts bring the expected result the ardent teacher suffers a defeat and the brave student triumphs.

The film God's Not Dead is described by the distributor as 'a fascinating philosophical dispute in the story about the search for answers to the most important question in the history of mankind'. This lofty, positive-value formulation raises some reservations. The reality presented in the film from the very beginning reveals a clear axiological trait - all the characters living in isolation from the Christian religion struggle with problems, are characterized by their selfishness and lack of sensitivity to others. There is, therefore, a clear opposition - the world of people who believe in Christ and the world of those who reject him. This is illustrated by the side plots of the film - including the story of a workaholic focused on 'crushing' her opponents with journalistic lampoons, her heartless partner who decides to break up with her upon learning about her illness, a brutal Muslim forcing his daughter to wear a headscarf and comply with the restrictive law that prevents her from functioning normally in society. All of these characters are practically caricatures and are based on certain patterns. An example is a scene in which the workaholic journalist, in response to the diagnosis, says 'I don't have time for cancer, I'm too busy', or when her partner responds to a suggestion to visit his mother says, 'I've already bought her a TV set'. The caricatured nature of these stereotypical images does not seem to be an intentional measure, since it does not cross the border beyond which the situations shown would provoke laughter. Rather, it is an attempt to reflect very bluntly the difficulties experienced by people living far from the world of moral and religious values.

The black-and-white nature of the world created in the film is most fully revealed in the juxtaposition of two main characters: the student 
ready to make sacrifices, faithful to himself, and the cynical lecturer who imposes his convictions on others. Professor Radisson is a negative figure - he is characterized by his disrespect for the freedom of others, malice (he describes faith as 'primitive superstition'), as well as a tendency to intimidate and treat his students dishonestly. From the first meeting of these characters, it is evident that the forces are unequal. The viewer is not able to sympathize with the lecturer and thus to take his ideas seriously. When it comes to the student gaining the advantage and the professor being forced to admit that he actually believes in the existence of God, but hates Him (because of personal childhood tragedy), the viewer accepts this solution without surprise. To put it bluntly, the scene of the student's victory is kitschy: both because of the aesthetic means used in it (tear-jerking music, pathos-filled clichéd acting), as well as its obviousness and pretentiousness resulting from the juxtaposition.

The figure of Josh, who represents the values most strongly promoted in the work, is elevated. His actions are based on his conviction that only a real threat is a test of faith. The decision to fight for the right to one's own convictions gains the rank of a radical and costly step in the film. As a result, the protagonist is abandoned by his girlfriend, threatened with the loss of social recognition and 'academic suicide'. However, all these dangers are nothing in comparison to Josh's belief that his actions are an expression of God's desires.

The creators of the film God's Not Dead had the ambition to show the persecution experienced by Christians: students do not have the right to freely express their faith, a girl brought up in an Orthodox Muslim family is brutally expelled from home when the fact that she practices Christianity comes to light. However, this issue is dealt with in a way that disregards the burden it contains. Banalization is achieved through conventionalization and the use of aesthetic means appropriate to pop-cultural messages (this is particularly evident in the scene of the girl being thrown out of a Muslim house, accompanied by a pop song with the phrase 'Carry on!' emphasized in the chorus). It would also be interesting from the point of view of reflection on the technical 'cheapness' of the film to analyze the scene preceding the 'busting' of the praying Christian woman by her Muslim brother: the camera following the subtle movements of the characters, the shot of the door and the twisting knob, contrasts causing a clear tension - all 
these are conventional elements of horror films. This borrowing causes through a kind of pretentiousness and inconsistency with the subject matter of the film - a comic effect, which seems to be not so much a deliberate action by the director as an unfortunate side effect.

The film is at the same time kitschy in terms of technique (artificial and stilted dialogue, incompetent acting, questionable directorial skills) and persuasive in a way that borders on propaganda (which is particularly strongly emphasized by a minor treatment blurring the line between fiction and reality - the film's closing inscription 'Join us and send a message to your friends'). However, it seems to reveal more than just the perfect coexistence of these two qualities. The kitschiness of the work reaches its extreme with a close intertwining with the procedures applied in order to 'intercept' the viewers, to reconcile them to the only correct, indisputable interpretation of the world, which is brought by Christianity, otherwise trivialized. The film does not have the character of a strictly evangelistic statement, but by creating a suggestive image of the believers of a certain religion - Christians - it strives to unify the image of the world, leaving the viewer without questions and doubts.

Similarly, conclusions can be drawn from the analysis of a work radically different aesthetically from God's Not Dead, namely Małgorzata Szumowska's 2015 film Body/Ciało. In this work, the phenomenon that interests me reveals itself very clearly. At first glance, on the basis of a superficial watching, it is difficult to consider Szumowska's latest film as a kitsch work. Body is certainly not technically mediocre - this is no place for an in-depth analysis of its individual layers; however, an intuitive viewing, supported by the voices of critics, allows us to conclude that we are dealing with a sophisticated and skillfully constructed work. The impression of 'cheapness' characteristic of kitsch is revealed only by the suggestive 'eloquence' of the film and, as the traceable testimonies of its reception indicate, it fails to be of a universal character. In order to look at the meaning of the final scene, it is worth to briefly reconstruct the plot briefly and interpret it.

Body tells the story of an orphaned family - Janusz and his daughter, Olga, suffering in the aftermath of the death of their loved one - wife and mother. This experience becomes the source of serious identity problems for the protagonists. Although it is not entirely clear if the experience is the cause of the father struggling with alcohol and becoming jaded, or the daughter's 
bulimic and suicidal tendencies, we observe their intensification in this context. Moreover, they both remain unreconciled with the death and loss of the loved person. In the case of the girl, this manifests in her longing (which she discusses with her therapist), in the case of the father - anxieties connected with fear of the dead wife interfering with his daily life. Janusz tenses when he watches a curtain fluttering, he is frightened as he turns off a radio that suddenly 'turned itself on', he deliberately and fearfully reacts to a neighbor's comments about loud music one of the household members allegedly heard. The film viewer does not see anything absurd in this anxiety, the series of small coincidences convincingly and coherently comes together into a picture of justified fear. Thus, the counterpoint for the worldview Janusz has built - rational, close to a cynically sardonic attitude - is the personally experienced fear, which on the one hand is an emotional reaction, and on the other the expression of doubts emerging on the intellectual level. In his daily existence, the protagonist has 'both feet on the ground', he is unmoved, and takes in news of the worst crimes - and even observes their traces - in an ostentatiously passionless way. The death of his wife changes this state of affairs - the uncertainty about the existence of life after death begins to creep into his world. This subject should be considered crucial for Body/Ciało, organizing its meanings, indirectly absorbing all the plots within it. The figure representing the spiritual world, rejected by the protagonist's belief in the possibility of communing with the dead and life after death is Anna, Olga's therapist and, as we find out later, a spiritualistic medium. Janusz initially reacts with reluctance to the woman, disrespecting her suggestions about how to take care of his daughter and above all the possibility of contacting his dead wife. With time, as his anxiety grows, his approach begins to change - he considers metaphysical issues, brings them up when talking to a friend, initiates a conversation with the therapist, and finally agrees to take part in a séance meant to contact his wife.

The scene of the séance is crucial for the dialogue developed in the film between skepticism towards metaphysics and the faith in its existence. The results of this experiment - as Janusz still perceives it in spite of everything - determine not only his attitude to the above-mentioned issue, but also the kind of diagnosis contained in the film - because we are dealing with leading the viewer through the complexities of the analyzed issue, 
creating the appearance of dialogue of rival arguments. When the séance turns out to be a failure - there are no signs of the presence of the deceased, and the medium falls asleep and starts snoring (which comically deepens the kind of devaluation of the world Anna represents) - the emotional and axiological horizon of the film is also cleansed. The last scene shows the glowing faces of two characters who, under the influence of Anna's falling asleep, are freed from anxiety and longing, and we see freedom and happiness in their eyes for the first time. This is accompanied by specific aesthetic means - joyful rock music plays, the room is flooded with warm morning light. The change that appears in the scene is clear and gives a sense of soothing, resolution and closure. Due to the conventionality of the tricks used to signal the banishing of the anxieties that tormented the protagonists, the scene may be described as kitschy or at least marked by kitsch. Kitsch appears in it - and here we come to the key issue - not only as conventional aesthetics, but also as the result of the persuasion inscribed in the film. The impression of cheapness, a kind of dishonesty, the feeling that the viewer has not been treated seriously, is the result of receiving an unambiguous, ready-made answer to questions inscribed in the experience of interacting with a complicated problem. Various artistically complex conceptualizations of the issue of corporeality and spirituality turn out to be aimed only at the conclusion that devalues their complexity that leaves no room for any doubts. One could, of course, ask about the sense of the last shot of the film the table at which the séance took place, seen from the outside. The sleeping woman is no longer there - has she fallen asleep and slid under the table? Has she been moved to her bed? Did she not exist at all? Or perhaps, in a direct paradox to the film's tone, she disappeared - as ghosts do - confirming her own ideas? This small shot allows us to see an element of openness in the structure of the film. It seems, however, that the weight of the kitschy resolution of the plot is not broken by this small trivial point, and it remains the 'last word' of the film.

The thesis indicating the possibility to identify as kitsch phenomena aesthetically different from the 'kitsch canon' and thus not representing the whole range of qualities associated with this category allows us to deepen our reflection on its complexity and situations when it goes beyond the purely aesthetic sphere. The directions of interpretation of selected cultural texts indicated in this text can be treated as an attempt to put into research practice 
theories taking into account the two planes of the influence of kitsch, its particular dual nature.

\section{Bibliography}

Andrzej Banach (1986), O kiczu, Kraków: Wydawnictwo Literackie.

Stanisław Barańczak (1984), Czytelnik ubezwłasnowolniony: perswazja w masowej kulturze literackiej $P R L$, Paris: Libella.

Marta Beszterda (2015), Sorbet z Sorrentino, „Czas Kultury”, online: http:// czaskultury.pl/czytanki/sorbet-z-sorrentino/.

Katarzyna Citko (2000), Kino komercyjne jako domena kiczu - tradycja i współczesność, [in:] Kicz, tandeta, jarmarczność w kulturze masowej XX wieku, ed. L. Rożek, Częstochowa: Wydawnictwo WSP.

Rafał Garpiel (2003), Perswazja w przekazach kaznodziejskich na przykładzie homilii Jana Pawła II wygłoszonych podczas pielgrzymki do Polski w roku 1979, Kraków: Nomos.

Milan Kundera (1984), The Unbearable Lightness of Being, transl. M.H. Heim, New York: Harper \& Row.

Abraham Moles (1978), Kicz, czyli sztuka szczęścia: studium o psychologii kiczu, transl. A. Szczepańska, E. Wende, Warszawa: PIW.

Ken-ichi Sasaki (2003), Głębsza retoryka. Mechanizm propagandy jako perswazji, transl. M. Bokiniec, „Estetyka i Krytyka”, No. 1.

Paweł Śpiewak (2011), Wstęp, [in:] S. Friedländer, Refleksy nazizmu: esej o kiczu i śmierci, transl. M. Szuster, Warszawa: Wydawnictwa UW.

Tomasz Paweł Wójcik (2000), Familiarność disco polo i brutalność heavy metalu. Zmierzch kultury czy nowa jej forma u progu XXI wieku, [in:] Kicz, tandeta, jarmarczność w kulturze masowej XX wieku, ed. L. Rożek, Częstochowa: Wydawnictwo WSP.

\section{Filmography}

Body/Ciało (2015), directed by Małgorzata Szumowska.

God's Not Dead (2014), directed by Harold Cronk.

\section{Summary}

The article concerns the problems of the relationship between kitsch and persuasion; it is an attempt to approach this relationship from two 
perspectives - indicating the persuasive nature of kitsch as one of its characteristics, and signaling the possibility of recognizing that the category of kitsch is present as a consequence of giving the message a persuasive character. The presented statements are based on the analysis of two films God's Not Dead, directed by Harold Cronk, and Body/Ciało, directed by Małgorzata Szumowska.

Keywords: persuasion, kitsch, manipulation, Harold Cronk, Małgorzata Szumowska 